\title{
THE GREATEST SCIENCE-FICTION STORY EVER WRITTEN
}

A real page-turner.

\section{BY ERIC JAMES STONE}

$\mathrm{I}$ tore open the self-addressed, stamped envelope and unfolded the single sheet of paper inside. The letter was signed by the editor of Analog Science Fiction and was addressed to me, personally, which still gave me a warm feeling after all those years of form rejections. But what I craved now was an acceptance.

And ... this wasn't it. Good luck placing this elsewhere, the letter read.

I shoved the rejection in my overstuffed file with the rest of them. Eyeing the four-inchthick wad of paper, I felt a wave of despair. Maybe I didn't have what it took to be a science-fiction writer. Maybe I should just give it up - after all, I worked for a quantum-computing start-up. That was almost science fiction, even if all I did was manage the website. Maybe that was as close as I'd ever get.

The next day, while having a mint Oreo shake at a restaurant near my office, I told Caleb, one of the quantum-circuit experts I worked with, that I doubted I'd ever see my name in print.

"Don't quit," he said. "You're a great writer." He'd read a few of my stories to give me feedback on where I'd got the science wrong.

I shrugged. "Doesn't matter, if I'm not writing what editors want to buy."

"Why don't you?"

"Why don't I? It's not that easy," I said. "There's no way of knowing what an editor will like. I write the best story I can, but apparently that's just not good enough."

"So it's subjective." Caleb took a bite of his burger and chewed thoughtfully.

"Yeah," I said, playing with the last spoonful of shake in my cup. "What one editor thinks isn't worth publishing, another might think is the greatest science-fiction story ever written. It's just my luck that the editor who would love my stuff isn't actually an editor anywhere."

"No, no," Caleb said. "You're looking at it all wrong. What you need is a story that adapts itself perfectly to the editor."

I dabbed my lips with a paper napkin. "I just told you I don't know how to write what they're looking for."

"Right." Caleb grabbed the napkin from my hand, flattened it out, took a pen from his pocket and sketched a curve. "It's a probability function. The right combination of words makes them buy the story, the wrong

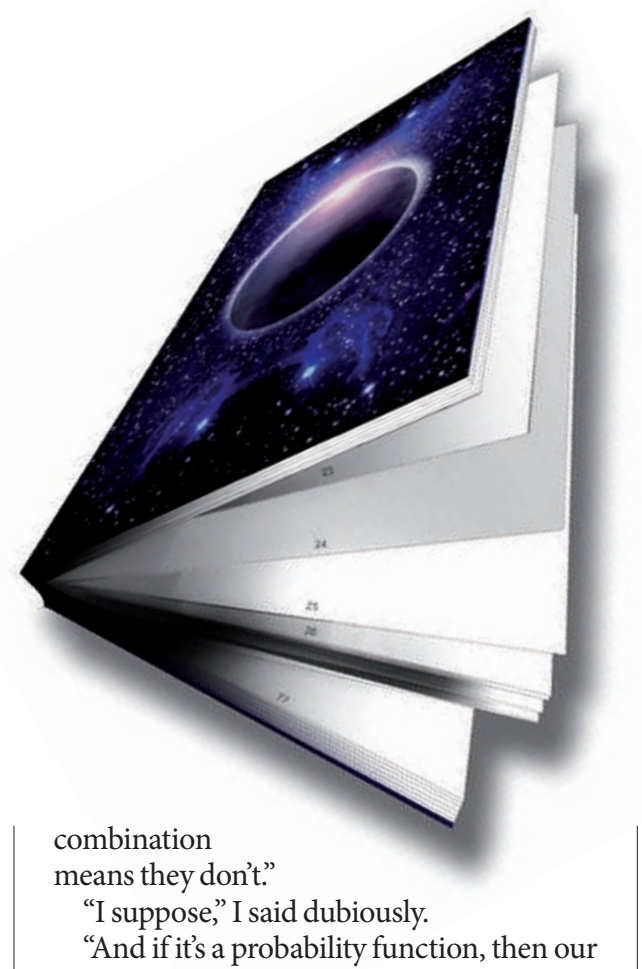

quantum computer can handle it." He scribbled an equation, crossed part of it out, then added something. "Oh, boy. This will revolutionize publishing."

I stared at him. "What are you talking about?"

He stopped scribbling. "Imagine you open a book, and from the very first word, it's exactly what you want to read. Every word is perfect, the characters fascinate you, the plot thrills you..."

“That'd be cool," I said.

"And someone else opens their copy of the same book, and it's perfect for them. Only if you compare the two books, the words aren't the same. The story and characters aren't even the same. The book has adapted itself to be the perfect book for whoever first opened it."

I frowned. "You mean, it's like an e-book that changes based on personal preferences?"

"No, this would be printed on paper. But the text itself would have been composed using a quantum computer, like the one we have at the office, using a program to create a quantum probability wave function that doesn't collapse until someone actually observes what was printed." Caleb sat back with a satisfied grin.

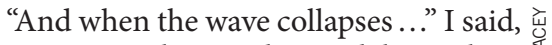
not quite sure that I understood the implications.

"The book becomes the best book ever written for whoever collapses the wave. It's brilliant." Caleb leaned forward. "And we can use it to make sure you get your name in print. How would you like to be the author of the greatest science-fiction story ever written?"

I stared at the sheets of paper lying facedown on the printer. "You're certain I can't take just a peek?"

"If you do," Caleb said, "the wave function will collapse and the story will become the best story for you, not for the editor of Analog. He needs to be the one to see it first."

"Can I at least know the title?" I felt kind of awkward submitting a story that I knew nothing about, even though Caleb assured me that I could still be considered the author, as the computer could not have been programmed to create a probability wave function for science-fiction stories without my help.

"Nope," he said. "I've hard-coded your name and contact information into the printout, but the rest remains undecided until the editor reads it."

With a sigh, I slid the manuscript into the manila envelope and sealed it.

Sixty days later, my SASE returned. I took it unopened to the office the next day - I wanted to open it with Caleb.

"Could be an acceptance or a rejection," I said.

"Open it," Caleb said, looking at the envelope. "You have to collapse the wave function. But I'm sure it's an acceptance."

I opened it.

"Read it out loud," Caleb said.

I looked past my name and began reading. "In my opinion, this is the greatest sciencefiction story ever written." My heart leapt within me, and I continued. "It is undoubtedly the best story you have ever submitted to me. But what on Earth made you think you could get away with submitting a verbatim copy of "Nightfall' by Isaac Asimov?" -

A Writers of the Future contest winner, Eric James Stone has had stories published in Analog, InterGalactic Medicine Show and various other venues. His website is www. ericjamesstone.com. 